\title{
Effect of Distributed Generation on Distribution Network and Simulation Analysis \\ Zou Qi ${ }^{1 a}$, Li Changchun ${ }^{1 b}$, Yang Guang ${ }^{1 \mathrm{c}}$ \\ ${ }^{1}$ Electric Power Science \& Research Institute of State Grid Tianjin Electirc Power Company, Tianjin,China, 300384 \\ azouqi1004@163.com ,'licc535@163.com, 'csuperyng@hotmail.com
}

Keywords: Distributed Generation, Simulation, Reliability

\begin{abstract}
The combination of distributed power supply and power distribution network is the main way to improve the flexibility and reliability of power system, which has the characteristics of high efficiency, energy saving and environmental protection. The characteristics and model of the solar photovoltaic power generation, wind power generation and fuel cell power generation are analyzed, and from the distribution of the voltage, power loss and power supply reliability several parties in the face of distributed current's influence on the distribution system was studied, and verified the correctness of the analysis through the simulation method, in order to provide reference for the rational allocation of distributed power supply.
\end{abstract}

\section{Introduction}

With the decrease of energy and the deterioration of environment, the defects of the traditional power system are becoming more and more obvious. Distributed power supply (DG) is a feature of environmental protection, high efficiency and flexibility, which has gradually attracted people's attention [1][2]. Therefore, based on the centralized power distribution model, the development of distributed generation technology is the inevitable trend of the development of new power grid with distributed generation. However, distributed power supply has brought a great influence to the modern electric power system, and the influence of power quality cannot be ignored [3].

This paper summarizes the characteristics of several typical distributed power supply and the model, and from the power energy quality, voltage distribution, power loss analysis the effect of distributed generation on the distribution system, also to IEEE6 node system as the simulation model, through simulation further illustrates the effect of distributed generation to the distribution network, provide a theoretical reference for the rational allocation of distributed power supply.

\section{Overview of distributed power supply}

Meaning and characteristics. Distributed generation (DG), also known as decentralized power generation or non centralized power generation, is the power generation units distributed in each load center and connected to the load, to achieve the nearest power demand load. Figure 1 Schematic diagram of photovoltaic power generation system.

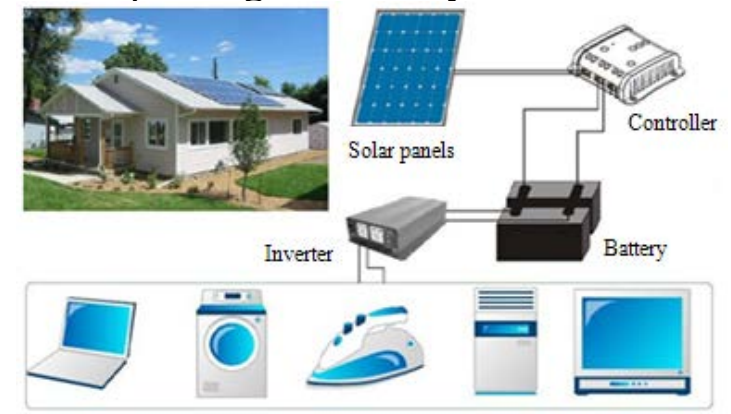

Fig.1 Schematic diagram of photovoltaic power generation system 
In the traditional distribution network access to distributed power generation, has many advantages:

\section{Environmental protection:}

Distributed power generation by wind, solar and other new energy power generation, thus reducing the emissions of harmful substances; and DG reduced traditional grid in large capacity and long-distance transmission line construction, reduces the high voltage transmission line loss and electromagnetic pollution and is conducive to environmental protection.

\section{Economic:}

Due to the high cost of transmission and distribution systems, the use of distributed energy can reduce the distribution costs in the case of the need to continue to increase the load. At the same time, due to the distributed generation units are generally close to the end of the user, the loss of line and transmission cost is greatly reduced.

\section{Safety and reliability:}

In the distributed generation system, each power station is independent of each other, and the user can control the power plant to avoid the occurrence of large-scale blackout. In addition, the distributed generation can continue to supply the power, make up the shortage of the security and stability of the power network.

\section{The main form and model of distributed generation}

According to the raw materials used in power generation, distributed generation can be divided into two kinds: one is to use renewable energy for power generation, such as wind power, photovoltaic power generation. Another is the use of non renewable energy power generation, such as diesel generators, fuel cell power generation.

\section{Photovoltaic cell generation}

Photovoltaic power generation is the use of photovoltaic effect of semiconductor solar cells solar radiation can be directly converted into electrical energy of a new generation, because has the advantages of no pollution, high efficiency characteristics has gradually become the main force of the new energy power generation[4]. Photovoltaic power generation is the direct current power, if the grid operation, need to be processed by the inverter, the DC power conversion into alternating current, its topology is shown in figure 2.

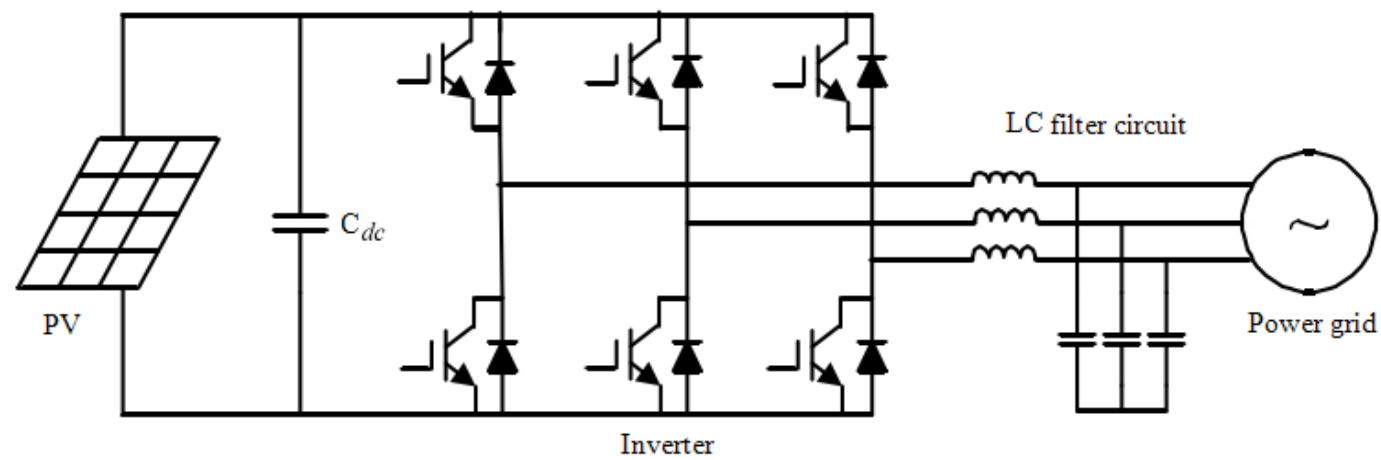

Fig.2 PV grid connected system structure topology diagram

The volt ampere characteristic of ideal photovoltaic cells is [5]:

$$
I=I_{g}-I_{0}\left\{\exp \left[\frac{q\left(V+I R_{C}\right)}{\mu K T}-1\right]-\frac{V+R_{C} I}{R_{B}}\right.
$$

Where:

$I_{g}$ - Light generated current ; $I_{0}$-Reverse saturation current ; $q$-Electron charge ;

$\mu$-Diode factor ; $K$-Boltzmann constant; $T$-Battery temperature;

$R_{C}$-Series resistor ; $R_{B}$-Parallel resistance.

2. Fuel cell 
Fuel cell is using electrochemical principle and to oxygen and hydrogen as fuel, through electrochemical reaction produced water, the conversion of chemical energy into electrical energy of a power generation, has the advantages of clean, efficient, and its power generation mode as shown in Figure 3.

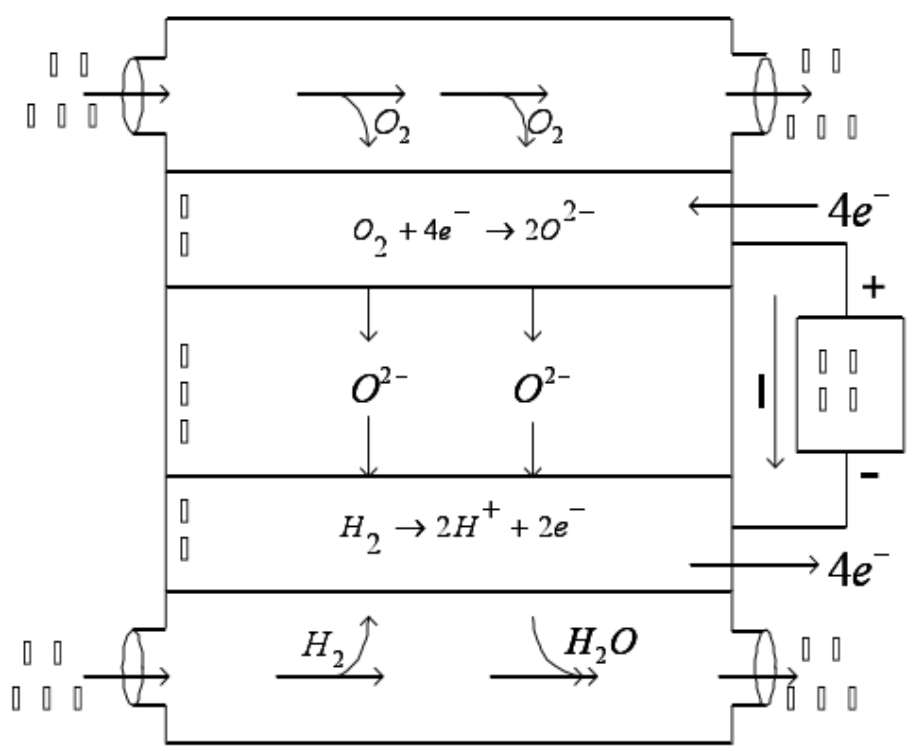

\section{Wind power generation}

Fig.3 Power generation principle of fuel cell

Wind power generation technology is a kind of power generation technology by means of converting wind energy into mechanical energy, and the mechanical energy is converted into electrical energy by generator. Wind energy has been widely used for its renewable and clean energy, and it is the most mature technology in the new energy development, its topological structure is shown in figure 4.

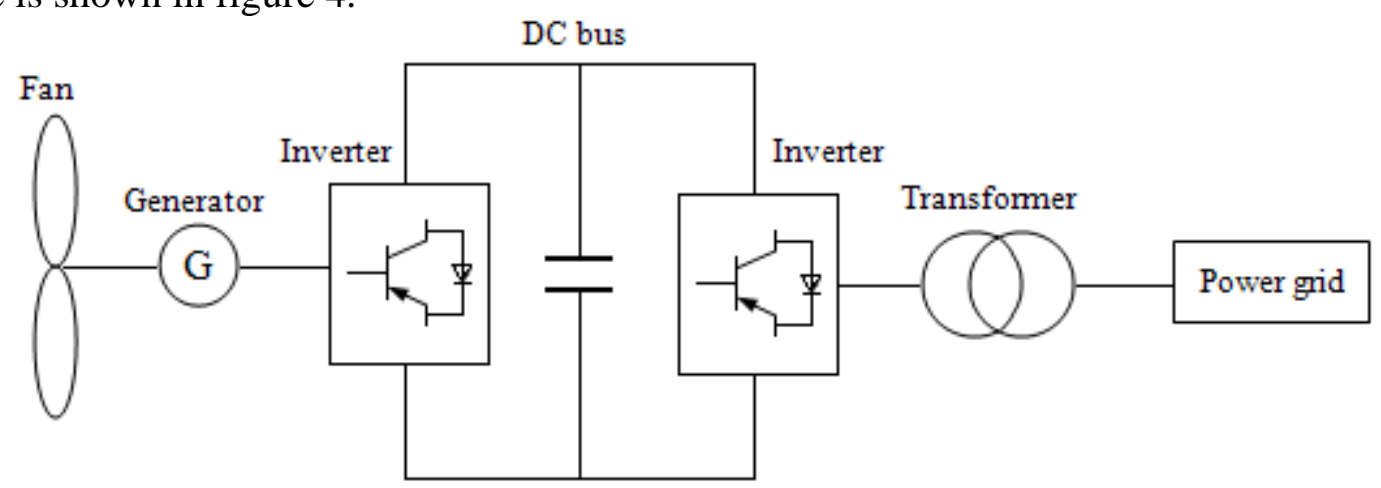

Fig.4 Topology of wind power generation

\section{Effect of distributed generation on distribution network}

Impact on power supply reliability. Distribution network access to distributed generation will improve the reliability of the system. When there is a fault in the distribution network, in the point of failure, repair at the same time, relying on distributed generation to power supply, reduce the inconvenience because of power failure to the user, so as to improve the system reliability. The reliability improvement is related to the location of the distributed generation, the more close to the client, higher the reliability is improved. When the distributed generation is shown in Figure 5 (a), the user of the fault point can be supplied by the distributed generation and the upstream of the fault point can be supplied by the power grid. When the distributed generation is shown in Figure 5 (b), it is not guaranteed that all users receive power supply when the fault occurs. 


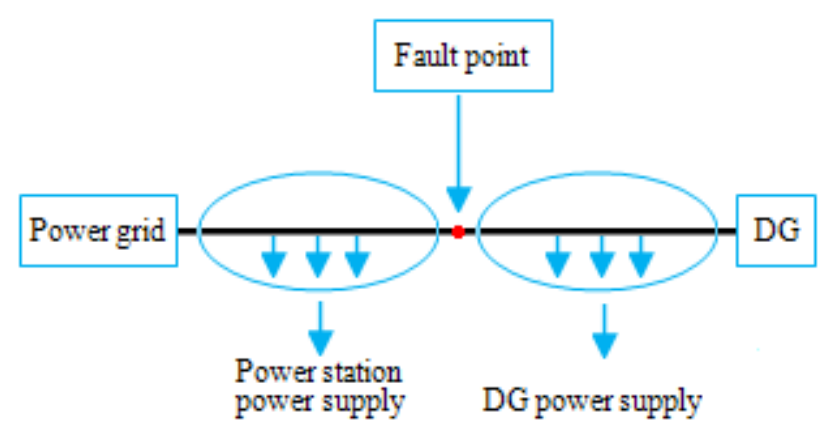

(a)

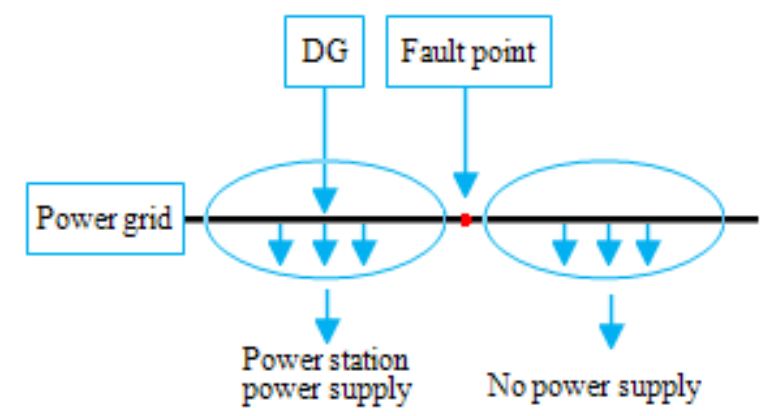

(b)

Fig.5 Effect of DG on power distribution system at different positions

Effect on voltage distribution. Voltage deviation is an important indicator of power quality, and the percentage of common voltage deviation is expressed:

$$
\Delta U \%=\frac{U-U_{e}}{U_{e}} \times 100 \%
$$

Where: $\Delta U \%$ - Percentage of voltage deviation ; $U_{e}$-Rated voltage; $U$-Node voltage.

In the distribution system, when the power transmission power is certain, with the increase of transmission distance voltage had decreased, when distributed power generation into the power distribution system, voltage just changed, as shown in Figure 6.

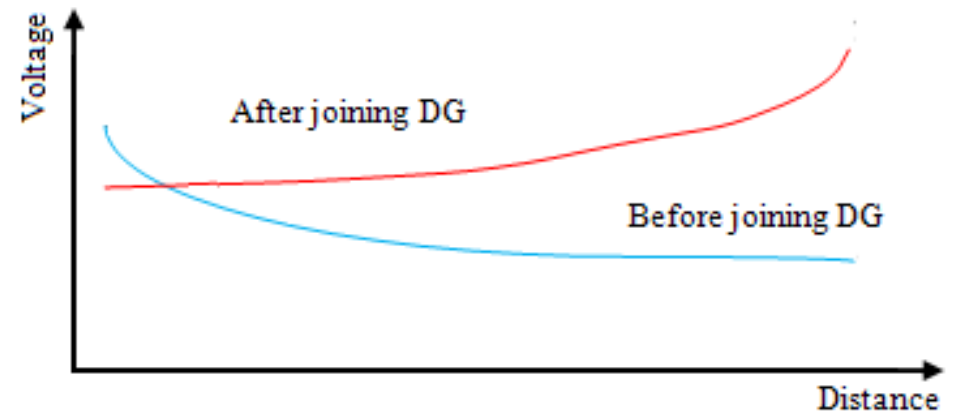

Fig.6 Effect of DG on voltage

\section{Simulation analysis}

Reasonable placement is application of distributed generation in distribution system is an important problem, and a reasonable position can effectively reduce the electrical loss of the system and improve the efficiency of the system, improve the system load current and voltage level. In the process of simulation, the effect of the distributed generation on the power distribution system is evaluated by using the network loss and power quality as the evaluation index. Figure 7 for the IEEE6 node distribution system.

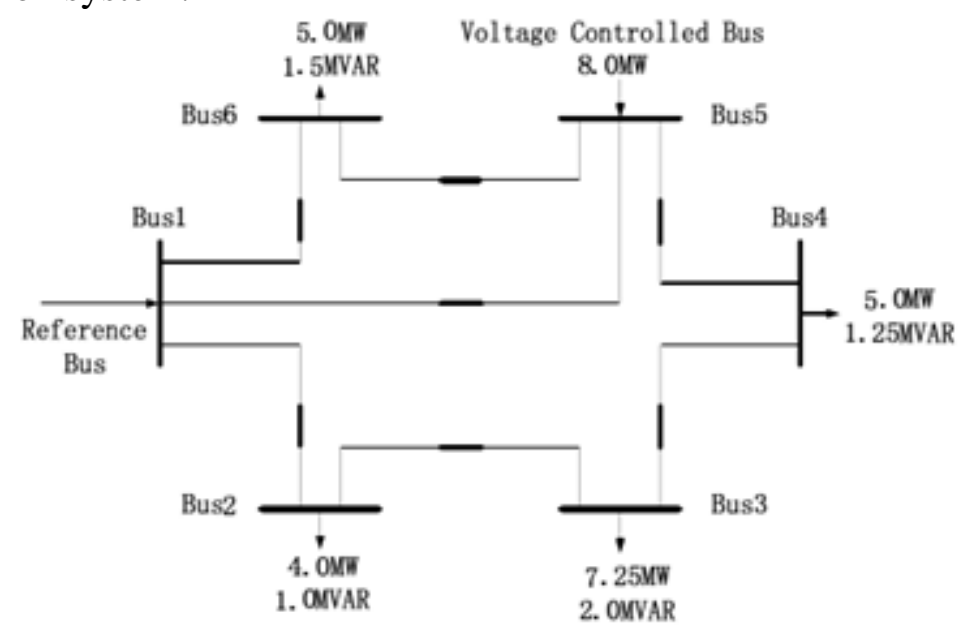

Fig.7 IEEE6 node distribution system 
Effect of DG on network loss. The distributed generation is placed in the node 2 6, and gradually increase the injection capacity of distributed generation, using MATPOWER software to solve the energy loss of the distribution system, as shown in table 1.

Tab. 1 Effect of DG on network loss.

\begin{tabular}{|cccccc}
\hline DG generating capacity & Bus $\mathbf{2}$ & Bus $\mathbf{3}$ & Bus $\mathbf{4}$ & Bus 5 & Bus 6 \\
\hline $\mathbf{1 0} \%$ & 1.208 & 1.118 & 1.135 & 1.386 & 0.106 \\
$\mathbf{2 0 \%}$ & 1.105 & 0.958 & 0.996 & 1.551 & 0.918 \\
$\mathbf{3 0 \%}$ & 1.032 & 0.860 & 0.933 & 1.810 & 0.102 \\
\hline $\mathbf{4 0 \%}$ & 0.985 & 0.812 & 0.945 & 2.158 & 1.336 \\
$\mathbf{5 0 \%}$ & 0.956 & 0.815 & 1.006 & 2.633 & 1.921 \\
$\mathbf{6 0} \%$ & 0.950 & 0.872 & 1.115 & 3.201 & 2.637 \\
\hline $\mathbf{7 0} \%$ & 0.978 & 0.978 & 1.289 & 3.816 & 3.586 \\
\hline $\mathbf{8 0} \%$ & 1.005 & 1.089 & 1.516 & 4.557 & 4.668 \\
\hline $\mathbf{9 0} \%$ & 1.060 & 1.269 & 1.812 & 5.417 & 5.904 \\
\hline $\mathbf{1 0 0} \%$ & 1.152 & 1.451 & 2.141 & 6.334 & 7.305 \\
\hline
\end{tabular}

According to table 1, the net loss curve of DG at different positions is obtained, as shown in Figure 8.

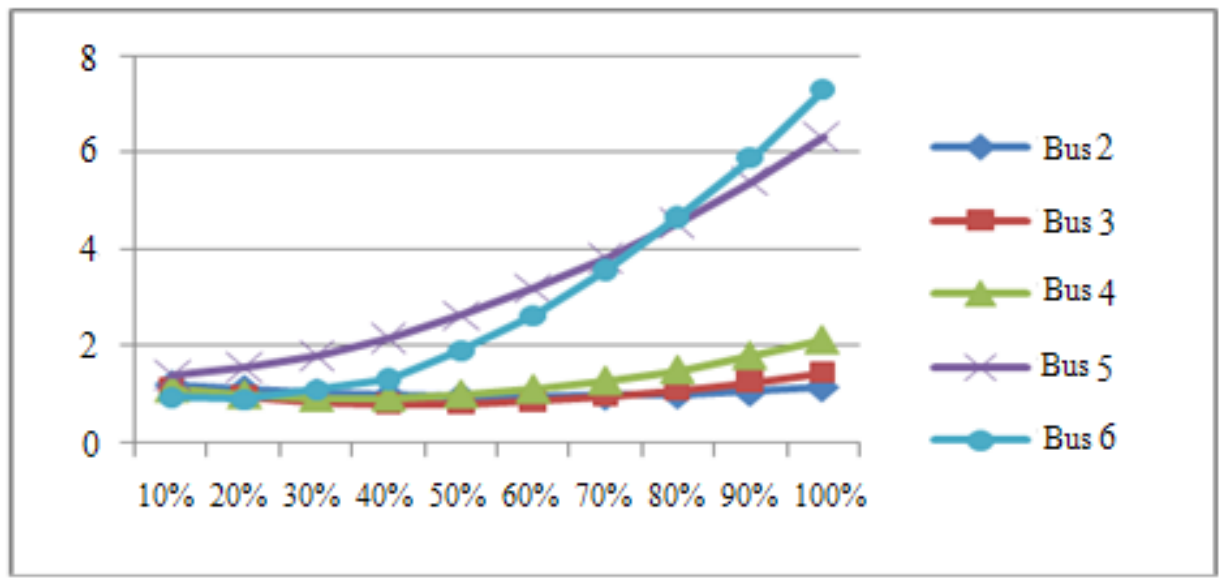

Fig.8 System loss curve

The results show that when the access of distributed generation to distribution system, near the load center near or distance power point far system network loss is lower, with the increase of system capacity, system efficiency improved, which can get the optimal location of the distributed generation.

\section{Conclusion}

The development and application of distributed generation has a great influence on the electric power system. How to make use of the characteristics of high efficiency and environmental protection in the distributed generation is the key to the development of power system. This indepth analysis of the model and characteristics of typical distributed generation, from two aspects of power distribution and power generation capacity of the specific study of the impact of distributed generation on power quality and the power losses, for the rational design of the power distribution scheme, give full play to the maximum system efficiency and provide a theoretical basis.

\section{References}

[1] Feng X, Liu J, Lee F C. Impedance Specification for Stable DC Distributed Power Systems[J]. IEEE Transaction on Power Electronics, 2002,17(2):157-162. 
[2] Vesti S, Suntio T, Oliver J A, et al. Impedance-based Stability and Transient-performance Assessment Applying Maximum Peak Criteria[J]. IEEE Transaction on Power Electronics, 2013, 28(5):2099-2104.

[3] Luo S. A Review of Distributed Power Systems Part I - DC DistributedPower System [J]. Aerospace and Electronic Systems Magazine, 2005, 20(8):5-16.

[4] Macau E N, Turci F R, Yoneyama T. Controlling Chaos in a Satellite Power Supply Subsystem [J]. The European Physical Journal Special Topics, 2008, 165(1):221-228.

[5] Caisheng Wang, M. Hashem Nehrir. Analytical approaches for optimal placement of distributed generation sources in power systems [J], IEEE Transaction on power systems, 2004, 19 (4): 94-98. 